- Familiarisation with the broad spectrum of contemporary materials allowing better-informed decisions to be made

- Discovering the factors that influence choice of alloys for indirect metallic restorations

- Knowing the pitfalls of selecting a cheap alloy for cast post and core construction

- Familiarisation with the different types of all ceramic crown and which ones can be used posteriorly

- An awareness of the many different types of metal copings for ceramo-metal restorations

- Consideration of the use of composite crowns for specific clinical situations

\title{
Crowns and extra-coronal restorations: Materials selection
}

\author{
R. W. Wassell ${ }^{1}$ A. W. G. Walls ${ }^{2}$ and J. G. Steele ${ }^{3}$
}

Materials selection is the second in the series on crowns and other extra-coronal restorations. Some of us are less than inspired by dental materials science. Nevertheless, many of the things that concern us clinically with crowns and their alternatives are based on material properties. We worry about the strength of the restoration, how well it fits and its aesthetics. We also worry about wear, occlusal control and biocompatibility. Not least of our concerns are dental laboratory charges, which inevitably have to be passed on to the patient.

CROWNS AND EXTRA-CORONAL RESTORATIONS:

1. Changing patterns and the need for quality

2. Materials considerations

3. Pre-operative assessment

4. Endodontic considerations

5. Jaw registration and articulator selection

6. Aesthetic control

7. Cores for teeth with vital pulps

8. Preparations for full veneer crowns

9. Provisional restorations

10. Impression materials and technique

11. Try-in and cementation of crowns

12. Porcelain veneers

13. Resin bonded metal restorations

${ }^{1 *}$ Senior Lecturer in Restorative Dentistry, 2Professor of Restorative Dentistry,

${ }^{3}$ Senior Lecturer in Restorative Dentistry, Department of Restorative Dentistry, The Dental School, Framlington Place,

Newcastle upon Tyne NE2 4BW

*Correspondence to: R. W. Wassell

E-mail: r.w.wassell@ncl.ac.uk

\section{Refereed Paper}

๑ British Dental Journal 2002; 192:

199-211
An understanding of the materials available, their application and limitations will not only help with selection but will allow more effective communication with patients and laboratories. Promotion of such understanding allowing better-informed decisions to be made is in essence the aim of this article.

There are now more materials available than ever before for indirect restorations. These fall under the broad headings of all metal, ceramics, metal-ceramics and resin composites. Cements and cementation, either conventional or adhesive will be considered in later articles. Manufacturers' details are shown at the end of the article.

\section{ALL METAL RESTORATIONS}

All metal extra-coronal restorations include crowns, onlays and shims (onlays relying soley on adhesive retention). Cast posts and cores can cause particular difficulties and are considered separately at the end of this section. In the UK as in other countries we are aware that economic pressures are driving the adoption of less expensive alloys. These alloys contain either low concentrations of noble metals or are comprised entirely of base metals.

In this section we consider the various types of alloys and the factors which influence their selection including:

- Cost

- Castability and handling

- Physical properties

- Resin bonding

- Corrosion and tarnish

- Biocompatibility
Gold and palladium alloys

In the 1950s making an alloy selection for a cast metal restoration would simply have entailed choosing an ADA specification high gold alloy, all of which had a greater than 75\% gold and platinum content. The soft type I alloy contained most noble metals (83\%) with the harder alloys (types II, III and IV) containing an increasing amount of silver and copper. Type I alloy was used for small inlays, type II for larger inlays, type III for crowns and bridges, and type IV for partial denture frameworks.

In the early 1970s the gold price increased four fold resulting in the introduction of less expensive alloys of lower Karat. ${ }^{1}$ Palladium, which had been used since the 1930s to produce a cheaper white gold (Au 30\%, Pa 10-35\%, Ag $35-60 \%$, Cu 6-25\%), became the noble constituent of many of the new precious alloys. These alloys include:

- Silver-palladium

- Palladium-silver-gold

- Gold-silver-copper-palladium (with a gold content greater than 40\%)

- Palladium-copper

- Palladium-tin

Palladium has a strong whitening effect which means that most of these alloys will have a silvery appearance unless the gold content is greater than $40 \%$ and the palladium less than $6 \% .^{2}$ Unfortunately, both palladium and silver absorb oxygen when molten, which can result in porous castings especially if casting buttons are reused. Also, reducing the gold content lowers the specific gravity (density), which may make casting less reliable than with high gold alloys. This is because less dense alloys have 


GOLD AND PALLADIUM
ALLOYS KEY POINTS:
- Porous castings can
result from reused
casting buttons
- Some alloys - especially
those of low noble
metal content - are
prone to corrosion
- The potential for
cheap alloys to cause
lichenoid reactions is
currently not known
but needs to be kept in
mind

\section{BASE METAL ALLOYS} KEY POINTS:

- $\mathrm{Ni}-\mathrm{Cr}$ alloys are popular in the USA but are effectively banned in Sweden

- A good bond strength can be achieved between certain $\mathrm{Ni}-\mathrm{Cr}$ alloys and resin luting agents

- Ni-Cr alloys are stiffer than most noble alloys and can therefore be used in slightly thinner section

- Technicians and dentists must avoid inhaling $\mathrm{Ni}-\mathrm{Cr}$ casting fumes or grinding dust especially if the alloy contains beryllium

- In patients sensitive to nickel it is best to avoid using $\mathrm{Ni}-\mathrm{Cr}$ alloys lower kinetic energy during casting which in turn reduces the penetration of molten metal into the mould. Nevertheless, some authorities argue that with ideal conditions almost all commercial alloys result in acceptable castings, ${ }^{3}$ but experience indicates that technicians may find such conditions difficult to achieve.

Tarnishing of some alloys is noticeable in certain patients, particularly around the margins of their restorations. This observation is born out by a five-year clinical study comparing two palladium silver alloys to a type III gold alloy. ${ }^{4}$ In the UK the National Health Service has encouraged the use of alloys containing only 30\% gold. The potential for corrosion problems to result from this change is currently unknown.

Allergies to gold, palladium and platinum are extremely rare. ${ }^{5}$ In-vitro studies ${ }^{6}$ show that high gold alloys have excellent corrosion resistance, which implies that few metal ions are eluted from restorations. Metal ions are eluted more easily from alloys of low noble metal content, including those of copper and silver. Copper ions have been implicated in producing lichenoid reactions. ${ }^{7}$ However, lichenoid reactions to metal ions from crowns are not as well described as for amalgam where many lichen planus series show up to a third of patients to be sensitive to mercury salts. ${ }^{8}$ This raises the possibility that some cases of lichen planus adjacent to crowns may be linked to the underlying amalgam core. Nevertheless, with current trends to use more easily corrodible casting alloys we should be alert to the possibility of more lichen reactions in the future.

\section{Base metal alloys}

Base metal alloys used to make indirect restorations include:

- Nickel-chromium

- Nickel-chromium-beryllium

- Titanium

- 'Progold'

\section{Nickel-chromium alloys}

The most commonly used base alloys are nickelchromium and nickel-chromium-beryllium. Beryllium is added to improve the alloy's physical properties; it is used as a hardener, grain structure refiner and to reduce the alloy's fusion temperature. ${ }^{9}$ As a result of health concerns (see below) some alloys contain molybdenum instead of beryllium. ${ }^{10}$ All of these alloys have a higher modulus of elasticity than noble alloys. This means that they are more rigid which is helpful in preventing flexion of long span bridges. Rigidity in thin section is necessary for adhesive bridge frameworks and for adhesively retained shims used to restore the palatal surfaces of worn incisors. It is also possible with selected resin adhesives to obtain high bond strengths to the surface of the sandblasted alloy. For instance Nery et al. ${ }^{11}$ reported a bond strength of $22 \mathrm{Mpa}$ for a nickel chromium alloy bonded to dentine with All Bond 2 (Bisco Inc,
Itasca, USA). A worrying trend, however, is for some laboratories to substitute a precious metal instead of nickel chromium without telling the dentist. Clearly, this could reduce the expected bond strength. ${ }^{10}$

Leaving aside health concerns for a moment, nickel chromium alloys are not without problems. Casting conditions need to be carefully controlled to obtain well fitting restorations and any technician will tell you that these alloys are hard to adjust and difficult to finish. This in turn can be a nuisance clinically when fitting restorations.

Experience of use differs markedly from country to country. In the USA these alloys have had a relatively good press ${ }^{12,13}$ and are used for casting crowns and bridges by the majority of laboratories. ${ }^{9}$ In the UK these alloys account for only $1 \%$ of the crowns provided on the National Health Service. In Sweden, the National Board of Health and Welfare has warned against the use of alloys containing more than $1 \%$ nickel, ${ }^{9}$ effectively precluding nickel-chromium alloys as they all contain between 62 and $82 \%$ nickel. ${ }^{14}$

The health problems are worth exploring in more detail. Many laboratories use non-beryllium containing nickel chromium alloys, as beryllium grindings and casting fumes are extremely hazardous unless controlled by an adequate exhaust and filtration system. Acute problems include conjunctivitis, dermatitis and bronchitis. Chronic beryllium disease may not express itself for several years after exposure. ${ }^{9}$ Similarly, nickel can cause technicians dermatological and lung problems with high levels of nickel or nickel compounds being carcinogenic. Tumours include rhabdomyosarcoma, nasopharyngeal and lung carcinomas. Again an effective exhaust system is needed to keep concentrations below recommended levels (Table 1). These levels vary from country to country, but if you are fitting nickel chromium restorations you should ensure adequate aspiration during adjustments.

Nickel is well known to cause contact dermatitis. Current estimates show that between $10-20 \%$ of women and 1-2\% of men are sensitised to the metal, possibly as a result of wearing nickel containing jewellery. ${ }^{15}$ Surprisingly, there have been few reports of patients reacting adversely to nickel containing dental restorations and little evidence that nickel adsorption intra-orally exacerbates existing dermatitis. Nevertheless, there are authorities that counsel dentists against using nickel in those patients known to be sensitive to the metal. ${ }^{5,14}$

Table 1 Nickel and beryllium are toxic. In the UK maximum permitted air levels (in $\mu$ g. $\mathrm{m}^{-3}$ ) of nickel for an eight-hour shift have recently been reduced five fold $^{78}$ but are still over six times higher than in the USA ${ }^{9}$

\begin{tabular}{lrr}
\hline & UK & USA \\
\hline Beryllium & 2 & 2 \\
\hline Nickel & 100 & 15 \\
\hline
\end{tabular}




\section{Titanium}

Titanium and its alloys are well known for biocompatibility. Restorations can be either cast or electro-formed. Casting requires high temperatures $\left(1650^{\circ} \mathrm{C}\right)$ and a special magnesium investment. ${ }^{16}$ Titanium oxidises easily so an argon arc is used to melt the metal and casting performed under vacuum. In 1985, Ida et al. ${ }^{17}$ reported that the fit of cast titanium crowns was intermediate between those made from a high noble alloy and nickel chromium. Electroforming was introduced in $1989^{18}$ and involves the milling of a titanium blank by spark erosion. Two year clinical follow-up of electroformed copings veneered with composite have shown encouraging results. ${ }^{19}$

\section{'Progold'}

Do not be misled by alloys such as 'Progold'. Like brass they consist largely of copper and zinc, and tarnish easily.

\section{Cast post and cores}

To avoid the post bending or breaking, the alloy chosen should have relatively high hardness, proportional limit and ultimate tensile strength. Occasionally, cost considerations drive the selection of the cheapest alloy, however corrosion and problems with castability should always be born in mind; porosity within a cast post can often result in post fracture with unfortunate consequences and thin posts are more likely to suffer critical porosity than thicker ones.

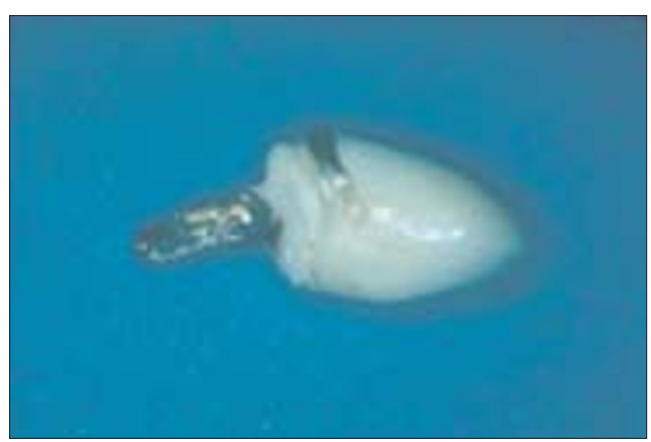

Fig. $1 \mathrm{~A}$ bent cast post has resulted in failure (note the failed composite cementation). Proper alloy selection and heat treatment will produce a more rigid casting, capable of resisting distortion from occlusal forces.

It is important to note that many gold alloys used for post and cores can be either soft or hard depending on heat treatment. A soft post will bend (Fig.1) and break more easily under occlusal load than a hard one. Laboratories may unwittingly produce soft posts simply by quenching the hot casting ring to allow the investment to be easily removed. If this is done the casting must be heat-treated according to manufacturer's specifications. The alloy used at our dental hospital (45\% Ag, 28.8\% Pd, 18.8\% $\mathrm{Cu}, 5 \% \mathrm{Au}, 0.6 \% \mathrm{Pt}$ ) is heat treated at $400^{\circ} \mathrm{C}$ for 20 minutes. In practice our technicians avoid the need for a separate heat treatment by allowing the casting ring to bench cool slowly to room temperature.

Some of the alloys used for all metal restorations can also be used for metal-ceramic restorations. However, we will first consider all ceramic restorations.

\section{ALL CERAMIC RESTORATIONS}

Dental ceramics, also termed porcelains, have a composite structure consisting of a crystalline phase or phases within a glassy matrix. Dental ceramics consist of oxides, largely of metals and silica, and are essentially inert materials, but we should be aware that they can be attacked by acidulated phosphate fluoride (APF) gel. Clinical experience with all ceramic restorations breaking under occlusal load confirms that these materials are generally susceptible to stress corrosion and slow crack growth. ${ }^{20}$

In 1965 McClean introduced aluminous porcelain. ${ }^{21}$ Until then only feldspathic porcelain had been available to make PJCs which although aesthetic was extremely brittle. Many of us would now consider aluminous porcelain as the standard material for PJCs. Nevertheless, despite it being a significant advance and highly aesthetic, aluminous PJCs are still prone to fracture and cannot be recommended as reliable means of restoring posterior teeth.

There are now a bewildering number of porcelain systems on the market and research is continuing to develop materials which are strong, aesthetic and suitable for multiple applications, including crowns, bridges, inlays and onlays. Some materials rely on the production of an opaque, heavily reinforced core over which weaker but more aesthetic layers of porcelain are built eg In-Ceram and AllCeram. Other materials have the strengthening agent dispersed throughout the material e.g. the glass ceramic, Dicor. Details of the strengthening mechanisms are well described elsewhere ${ }^{22}$ but all of them rely on having a crystalline phase dispersed within a glassy matrix.

Traditionally, porcelains are classified as high fusing, medium fusing or low fusing but this is not terribly helpful in understanding the increasing number of materials available. Aluminous porcelain PJCs are made simply by sintering (see later) but there are five other methods of making indirect porcelain restorations which together form a useful means of classification:

- Sintered Porcelains

- Glass Infused Ceramics

- Cast Glass Ceramics

- Hot Pressed, Injection Moulded Ceramics

- Machined Glass Ceramics

- Machined Densely Sintered Ceramics

We will first consider some of the materials within this classification and then look at the major clinical factors that influence material choice.
TITANIUM KEY POINTS:

- Specialised casting requires an argon arc under vacuum

- Restorations can also be 'electroformed' using spark erosion

CAST POST AND CORES KEY POINTS:

- Avoid cheap alloys which may corrode or cast poorly

- The alloy needs to have a high modulus of elasticity and high yield strength

- Proper heat treatment ensures a stiff post which is less likely to bend 


\section{ALL CERAMIC RESTORATIONS KEY POINTS: \\ - Ceramics are considered inert but can be attacked by APF gel \\ - Ceramics are strength- ened by the dispersion of a crystalline phase through a glassy matrix \\ - Ceramics can be classified according to fusion temperature and mode of manufacture \\ - Ceramic systems cannot be evaluated on strength data alone \\ - In-Ceram and Procera Allceram are suitable for posterior crowns based on long-term clinical evaluation \\ - Resin bonding of In-Ceram requires specific silanisation techniques}

\section{Methods of making indirect porcelain restorations}

\section{Sintered porcelains}

Sintered porcelains are built up from an aqueous slurry of porcelain particles condensed onto a platinum foil matrix or a refractory die. Sintering occurs at a temperature above the softening point of porcelain whereby the glassy matrix partially melts and the powder particles coalesce. There is volume shrinkage of $30-40 \%$. Porosity can be reduced from 5.6 to $0.56 \%$ by vacuum firing. ${ }^{23}$ Sintering is the most commonly used technique of making PJCs and veneer restorations with a number of different materials available:

- Aluminous porcelain eg Vitadur-N, Hi-Ceram

- Feldspathic porcelain reinforced with Zirconia fibres eg Mirage II

- Feldspathic porcelain reinforced with leucite eg Optec HSP

\section{Glass infused ceramics}

In-Ceram is a glass infused ceramic used for crowns (Fig. 2). It consists of a core containing $90 \%$ alumina, which is built up on a refractory die. During firing, at $1150^{\circ} \mathrm{C}$ for four hours, the die shrinks so that it can be withdrawn from the core. This process (which is also used to manufacture ceramic lavatory pans) is called 'slipcasting'. At this stage the core is a weak, porous structure consisting of partially sintered alumina particles. Strength is conferred by painting a slurry of lanthanum containing glass onto the outside of the core and refiring it. During refiring the molten glass is drawn into the porous structure thus eliminating voids and creating a glass-ceramic composite. The excess glass is ground away and porcelain with a matched coefficient of thermal expansion is built onto the surface. The manufacturers recommend that restorations be cemented with conventional acid base cements.

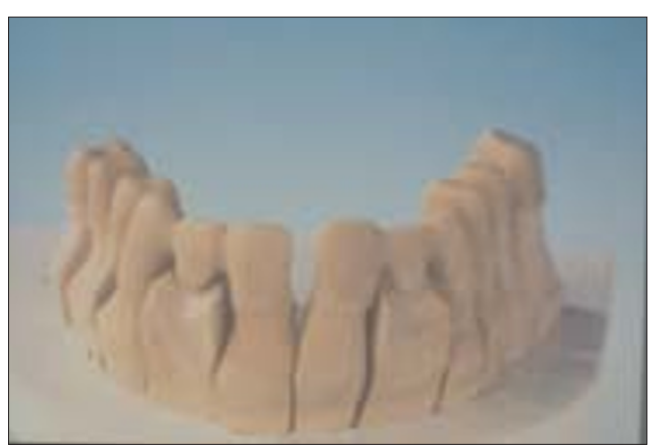

Fig. 2 In-Ceram glass infused alumina cores prior to porcelain application (Courtesy of Vita)

In-Ceram Spinnel is a similar type of material but uses the less hard magnesium spinnel $\left(\mathrm{MgAl}_{2} \mathrm{O}_{4}\right)$ instead of alumina. The material is specifically designed for inlays and onlays. Most recently introduced is In-Ceram Zirconia, which has a very high flexural strength.

A novel material called Techceram has been introduced in the UK, which also relies on having a glass infused core. The core is built of small 'splats' of alumina sprayed from a plasma gun at a rotating refractory die. Again, after glass infusion, the restoration is formed conventionally on the core with a matched sintered porcelain. The company claim a flexural strength as high as for In-Ceram.

\section{Cast glass ceramics}

Glass ceramics are polycrystalline solids prepared by the controlled crystallisation of glasses. The best known of these systems, Dicor, is based on mica crystals although there is another, Cerapearl, based on hydroxyapatite and experimental lithia-based materials. ${ }^{24} \mathrm{~A}$ Dicor restoration is made by investing a wax pattern and casting. Heating the reinvested crown for six hours at $1070^{\circ} \mathrm{C}$ carries out controlled crystallisation, termed 'ceraming'. This causes the Mica to form a strong 'house of cards' structure, which makes fracture propagation equally difficult in all directions. However, a reaction between the mica and the surrounding investment may result in a weakened surface layer, which reduces significantly the overall strength of the material. ${ }^{25}$ Characterisation of the crown is achieved by surface glaze. Prior to glazing the material has the appearance of frosted glass.

To overcome the limitations of surface glaze, which are considered in more detail later, a technique of laminating a Dicor coping with feldspathic porcelain has been developed with the intriguing name 'Willi's Glass'. ${ }^{26}$ Providing the correct porcelain (Dicor Plus) is used for lamination, the strength of the restoration should not be adversely affected. ${ }^{27}$

\section{Hot pressed, injection moulded ceramics}

IPS Empress is a leucite containing porcelain. As with cast glass ceramics the restoration is first waxed-up and invested, however the ingot, which is made of sintered ceramic, is not molten but softened before being pressed into a mould under pressure at $1150^{\circ} \mathrm{C}$ (Fig. 3). The pressure is maintained for 20 minutes during which time the tetragonal leucite crystals are dispersed throughout the restoration giving a 40\% concentration by volume. The shade of the ingot provides the basic shade, which can be modified by either glazing or veneer porcelains. To ensure compatibility with veneer porcelains the ingots have a lower coefficient of thermal expansion $\left(14.9 \times 10^{-6} /{ }^{\circ} \mathrm{C}\right)$ than those for the glazed material $\left(18 \times 10^{-6} /{ }^{\circ} \mathrm{C}\right)$. The application of veneer porcelains may require multiple firings that can enhance the strength of the material. ${ }^{28}$

Another material, less well known in the UK is Alceram, which is based on magnesium spinnel. It is important to emphasise that this is a quite different material to the much stronger Procera AllCeram which is mentioned later.

\section{Machined glass ceramics}

There are a number of milling systems available for milling ceramic blanks, ${ }^{29}$ which may be con- 


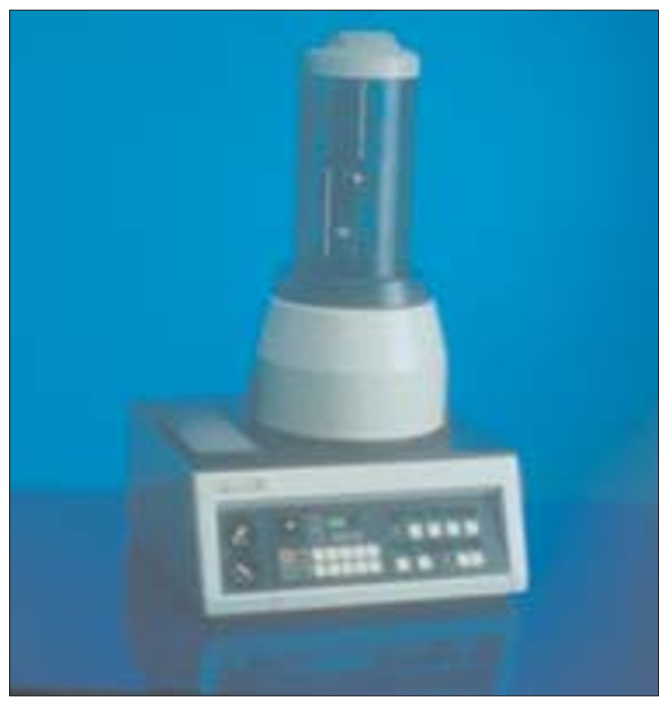

Fig. 3 The press ceramic furnace used for the construction of injection moulded IPS Empress crowns (Courtesy of Ivoclar).

trolled either by computer aided design/computer aided manufacture (CAD/CAM) or mechanically. The best-known CAD/CAM system in the UK is Cerec and the best-known manual system is Celay. Both of these machines were introduced for inlays and onlays, but the original Cerec 1 software gave questionable marginal fit. ${ }^{30-32}$ The accuracy of fit is better with Cerec $2^{33}$ and may be improved still further with the recent introduction of Cerec 3.

The ceramic blanks are manufactured to higher levels of strength than can be achieved manually in the dental laboratory. Materials include Dicor MGC, Vita Mark II and Vita Celay; the latter two contain sanidine $\left(\mathrm{KAlSi}_{3} \mathrm{O}_{8}\right)$ as the crystalline phase. Unfortunately, sanidine makes the ceramic very opaque. ${ }^{22}$ A newer material, Corning MGC-F is a tougher material with a higher flexural strength. ${ }^{34}$

Despite the relatively high strength of the ceramic blank, machining may cause weakening through the introduction of surface flaws. ${ }^{35}$

\section{Machined densely sintered ceramics}

Procera AllCeram is a densely sintered, high purity alumina core on which low fusing porcelain is built. ${ }^{36,37}$ AllCeram cores have some of the highest measurements of flexural strength yet recorded for a commercially available system. Despite this, even stronger materials based on zirconia are being developed.

Interestingly, the cores are made centrally in Sweden or New Jersey, USA. Local dental laboratories scan the dies (Fig. 4) and the information is sent to one of the two centres via the Internet enabling oversized dies to be made. The dies are oversized to compensate for the shrinkage of alumina during sintering. A mixture of alumina and binder is pressed onto the dies under pressure and, before sintering, machined to the required thickness $(0.25,0.4$ or $0.6 \mathrm{~mm})$. In this way any small defects caused by machining are eliminated during sintering. The thicker cores are recommended for posterior teeth and the thinner cores for veneers. The $0.4 \mathrm{~mm}$ cores are used for aesthetically critical crowns on anterior teeth and first premolars.

\section{Choice of ceramic system}

When faced with the task of evaluating a new or alternative ceramic system you should have a number of questions in mind - as considered under the six headings below.

\section{Should I choose the strongest ceramic?}

The flexural strength of ceramics is often quoted (see Table 2 for moduli of rupture), but it is worth pointing out the limitations of such data (see later) before automatically choosing what appears to be the strongest system on the list.

- Fracture toughness and fatigue are also important

- Comparisons between tests may be unreliable ${ }^{38,39}$

- An In-Ceram core, although strong in itself, is weakened by increasing the thickness of overlying ceramic ${ }^{40}$

- Resin cements are an important adjunct to the strength of the finished restoration. This concept has been shown with veneers. ${ }^{41}$ A poor bond of resin to tooth or restoration will not enhance the strength of the cemented restoration. Some ceramic cores are smooth internally and resistant to etching with hydrofluoric acid (eg In-Ceram), which prevents effective resin bonding unless specific silanisation techniques are used..$^{42,43}$

- Some ceramic veneers omit the strengthening core and rely mainly on the resin bond to enhance the strength of the comparatively weak veneering ceramic.

\section{How much tooth reduction is needed?}

Most systems specify a similar amount of tooth reduction as for a conventional alumi-

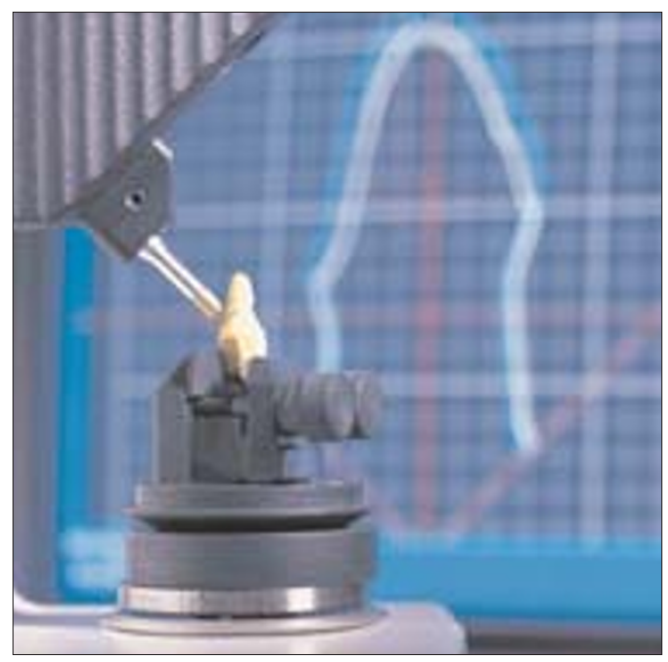

Fig. 4 A die is scanned for a Procera AllCeram coping (outline of scan is in the background), which is made centrally in either Sweden or the USA (Courtesy of Nobel Biocare) 


\begin{tabular}{|c|c|c|c|}
\hline \multirow[b]{2}{*}{ Crystalline Phase } & \multicolumn{2}{|c|}{ Sintered Porcelains } & \multirow[b]{2}{*}{ Reference } \\
\hline & Example & lexural Strength (MPa) & \\
\hline Aluminous (Pt foil) & Vitadur-N & 123 & 79 \\
\hline Aluminous (refractory die) & Hi-Ceram & 139 & 79 \\
\hline Leucite reinforced & Optec HSP & 104 & 79 \\
\hline \multirow[t]{2}{*}{ Zirconia based } & Mirage II & 70 & 79 \\
\hline & \multicolumn{2}{|c|}{ Glass Infused Ceramics } & \\
\hline Alumina based & In-Ceram & 446 & 80 \\
\hline Magnesium spinnel & In-Ceram Spinnel & 378 & 80 \\
\hline \multirow[t]{3}{*}{ Zirconia } & In-Ceram & 604 & 80 \\
\hline & Zirconia & & \\
\hline & \multicolumn{2}{|c|}{ Cast Glass Ceramics } & \\
\hline \multirow[t]{2}{*}{ Mica based } & Dicor & 125 & 79 \\
\hline & \multicolumn{3}{|c|}{ Hot Pressed Injection Moulded Ceramics } \\
\hline \multirow[t]{2}{*}{ Leucite based } & IPS Empress & 97 & 80 \\
\hline & & $160-180$ & 28 \\
\hline \multirow[t]{2}{*}{ Zirconia and Alumina } & Alceram & 162 & 81 \\
\hline & \multicolumn{3}{|c|}{ Machined Glass Ceramics } \\
\hline Mica based & Dicor MGC & 229 & 80 \\
\hline \multirow[t]{2}{*}{ Sanidine } & Vita Mark II & 122 & 80 \\
\hline & \multicolumn{3}{|c|}{ Machined Densely Sintered Ceramics } \\
\hline Alumina & Procera AllCeram & 687 & 36 \\
\hline
\end{tabular}

nous PJC; that is a $1 \mathrm{~mm}$ shoulder and 1.5 to $2 \mathrm{~mm}$ incisal reduction for anterior teeth and $2 \mathrm{~mm}$ occlusal reduction for posterior teeth. A $1.2 \mathrm{~mm}$ axial reduction is specified for In-Ceram but a much heavier axial preparation is needed $(1.5 \mathrm{~mm})$ when Dicor crowns are prescribed for posterior teeth. Many dentists will find this unacceptably destructive of tooth tissue or they simply will not cut it and then wonder why the crown fractures.

Do all ceramic restorations fit well?

The marginal fit of indirect restorations is for many dentists an emotive but inconclusive subject. There is currently no consensus as to what constitutes an unacceptable marginal opening 44 although clinical experience and empirical data suggest $100 \mu \mathrm{m}^{45}$ especially where the margin can only be probed. ${ }^{46}$ No relationship has been found between size of marginal opening and microleakage, ${ }^{47}$ however an open margin will predispose to loss of cement lute, which has implications for secondary caries and periodontal disease. ${ }^{48}$

Most marginal fit data is from in-vitro studies where variables are carefully controlled but unfortunately comparisons of crown types are limited and studies cannot be compared because of differences in methodology. Also, measurements can be made difficult by rounding of shoulder ceramic margins. These in-vitro studies generally show mean marginal openings in the $20-80 \mathrm{~mm}$ range and while statistically significant differences can be shown between systems ${ }^{49}$ the clinical relevance is unclear. However, as already mentioned ${ }^{1}$ some of the machined ceramic restorations have much greater discrepancies. Those would certainly be problematic if the restorations were cemented with conventional cements.

A common perception is that the most reliable margins are achieved with metal rather than with ceramic. Whilst this contention is supported by some studies ${ }^{49}$ others do not support it. ${ }^{50}$ Clearly technical skill will play a large part in achieving satisfactory results with whatever system is chosen. Comparing ceramo-metal crowns to metal crowns with all ceramic crowns the former generally have better resistance to marginal distortion from repeated firings than the latter, which has implications for some all ceramic systems where the ceramic is applied incrementally. ${ }^{51}$ In-Ceram, however, has good resistance to multiple firings. ${ }^{52}$

\section{Will the system be aesthetic?}

Although all ceramic restorations have the potential to provide the best aesthetics, aesthetics are material and skill dependent. Obtaining a good result is not simply a matter of colour matching. Translucency, which is determined by the match in reflective indices of the crystalline phase and surrounding matrix, is also important. Better control of colour can be achieved by building it into the substance of the restoration rather than merely relying on surface glaze which may wear thin with time or be removed with adjustments. Some of the systems described above are coloured entirely by surface glazing.

\section{Will the restoration abrade the opposing} tooth?

Ceramic has a reputation for causing wear to opposing tooth structure. This is born out by invitro studies, ${ }^{53}$ and certainly there is a potential for greater wear if ceramic is left rough after occlusal adjustment. ${ }^{54}$ It is currently not clear if one type of ceramic is markedly less abrasive than the others, although the mica-glass, Dicor, the machinable glass Vita Mark II and the low fusing ceramics (eg Procera and Duceratin) have shown a trend in this direction. ${ }^{55,56,57}$ The situation is complex however; chemicals in foodstuffs (eg cola drink) may affect some low fusing ceramics resulting in them becoming more abrasive and less resistant to wear. ${ }^{58}$ Further research is needed before dentists can confidently prescribe ceramic occlusal surfaces with similar abrasivity to gold.

Is the system supported by meaningful clinical studies?

The problem with clinical studies is that they take time. Longevity data at one or two years is of limited use unless it is showing a high failure rate. Also clinical success with anterior crowns can not be extrapolated posteriorly; a 3-year trial of Dicor molar crowns resulted in a failure rate of $64 \%$. With the brittle characteristics of all ceramic restorations, a trial of 5 years is preferable to be confident of future performance. Good data is available for In-Ceram ${ }^{59,60}$ and for Procera AllCeram ${ }^{61}$ showing fracture levels of less than $1 \%$ per year. 
Are all ceramic bridges possible?

It is possible to make small anterior bridges with most of these systems, but with the exception of Vita's In-Ceram few manufacturers actively promote this because of the risk of fracture, especially at the connectors. The Procera AllCeram specifies a minimum connector height of $3 \mathrm{~mm}$ and a maximum span of $11 \mathrm{~mm}$. Clinical studies are underway but long-term results are not yet available.

\section{Cost?}

The cost of high strength ceramic restorations such as In-Ceram, AllCeram and Empress will take into account a laboratory's investment in new equipment and training as well the time taken to make a restoration. In the UK, high strength ceramic crowns are up to $£ 40$ to $£ 60$ more expensive than an aluminous PJC. These materials can be used on the National Health Service but not without prior approval. If approved, a discretionary fee is awarded which in most cases will not cover the laboratory bill.

\section{METAL-CERAMIC RESTORATIONS}

Stress concentrations within PJCs often lead to cracks propagating outwards from the fit surface of the restoration. A comparatively tough metal coping effectively bonded to the ceramic will help stop cracks developing in this way. The first metal copings were cast but other methods of coping construction, including foil and metal composite copings, have since been developed.

\section{Cast copings}

Porcelain fused to metal (metal-ceramic) technology was first described in $1956^{62}$ and patented in $1962 .{ }^{63}$ Alloys were produced with melting points sufficiently high to resist the firing of porcelain. The first alloys had a high noble metal content of around 98\% with iron, indium and tin used for hardening, and to create a superficial oxide layer to which the ceramic could be bonded. The ceramic had to be specially formulated to have a high coefficient of thermal contraction to prevent unwanted stresses being built up between it and the coping on cooling after firing. This was achieved with a ceramic containing 15-25 vol\% leucite as its crystalline phase.

With such a high gold content the original alloys were extremely expensive, resulting in many laboratories preferring high palladium low gold alloys - although paradoxically, palladium prices have recently been so high that the high gold alloys are sometimes the more affordable alternative! High palladium alloys have the advantage of having a high modulus of elasticity and are therefore more rigid allowing slightly thinner copings to be made. This rigidity is particularly useful in bridgework where flexion of the pontics under load can result in fracture of the overlying porcelain. The alloy used by our dental hospital contains $78.5 \% \mathrm{~Pa}, 6.9 \% \mathrm{Cu}$, 5.5\% Ga, 4.5\% In, 2\% Sn, 2\% Au. Other alloys also contain either gallium or indium or both to promote chemical bonding to the porcelain. ${ }^{10}$
Some of the alloys already considered under 'all metal restorations' can be used for metalceramic copings. These include nickel chromium, nickel chromium beryllium, silver palladium alloys and titanium.

Control of the oxide layer thickness is important to avoid problems of porcelain debonding. Some silver palladium alloys can cause a greenish hue to appear due to diffusion of silver compounds into the porcelain. Titanium oxidises easily and a thick nonadherent oxide layer can form under regular feldspathic porcelains. Thus low fusing porcelains (eg Procera or Duceratin) are used to avoid problems of the oxide layer compromising strength. ${ }^{64}$ Porcelain bond strengths to titanium are in any case not as high as with other alloys which may explain the higher risk of metal-ceramic failure seen in a 6-year clinical follow-up. ${ }^{65}$

Low fusing 'hydrothermal' porcelains (Duceram, Duceragold) can also be fused to type IV gold in what is known charmingly as the 'Golden Gate System'. Once again control of the oxide layer is crucial for achieving bonding and good aesthetics. ${ }^{66}$ Aesthetics are improved by the underlying gold shining through the porcelain. The major perceived advantage of this system is the potential to limit the number of different alloys used in a patient's mouth.

Cast copings are the most commonly used method of strengthening porcelain and have served us well, but consistently good aesthetics are difficult to achieve because the metal has to be covered by an opaque layer which in turn limits the thickness of an adequate overlying layer of porcelain. However, proper tooth reduction and excellent technical support will largely overcome this problem.

One of the main advantages of cast copings is that the coping can be waxed to create a metal occlusal surface - a facility that is either absent or more difficult to achieve in the following two systems.

\section{Foil copings}

In 1976 McClean ${ }^{67}$ reported a technique of fusing platinum foil to the fit surface of an aluminous PJC. The foil was made adhesive to the porcelain by electroplating with tin and subsequent oxidisation. The crown was made using two layers of foil with the first layer being removed after firing. ${ }^{68}$ Any improvements in compressive strength are controversial with some reports showing a positive effect and others negative. ${ }^{69}$ Such differences are explained by variations in test methodology. Other foils have been tried with aluminous porcelain including palladium ${ }^{70}$ and gold coated platinum..$^{71,72}$ More recently a gold foil reinforced crown has been introduced. ${ }^{73}$ The foil of this 'Sunrise Crown' is $50 \mu \mathrm{m}$ thick and contains gold, platinum and an oxidising element designed to facilitate porcelain bonding. Unlike platinum foil, the gold alloy has too high a coefficient of thermal expansion to be used with aluminous porcelain. Standard metal-ceramic porcelains are used
METAL-CERAMIC RESTORATIONS KEY POINTS:

- High palladium low gold alloys have significant advantages over high gold alloys where rigidity is needed

- Oxides of gallium, indium and tin are used to promote adhesion of alloy to ceramic

- Too thick an oxide layer can result in ceramic debonding or discolouration

- A metal occlusal surface can be incorporated in a cast coping but not in foil copings

- Foil copings are not strong enough for posterior restorations

- Metal composite copings (Captek) are a promising alternative to cast copings where the occlusion is to be built in porcelain

- Electroformed copings are an interesting but unproven technology

- Surface treatment of the ceramic by ion exchange gives only limited strengthening 
instead. These crowns can fit well ${ }^{74}$ but measurements of compressive strength are unimpressive, ${ }^{73}$ and, in the absence of clinical trials to the contrary, do not support their use for restoring posterior teeth.

\section{Metal composite copings}

The Captek system was developed over a decade ago for producing composite metal frameworks for metal-ceramic crowns, bridges, inlays and onlays (Fig. 5). The technique, which involves the fabrication of a metal composite (Fig. 6) coping (88\% Au, 4\% $\mathrm{Pt}, 4 \% \mathrm{~Pa}$ ) is comparatively simple but does require some technician training. ${ }^{75} \mathrm{~A}$ metal impregnated wax sheet is adapted over a refractory die, sintered in a porcelain furnace, and the resulting granular structure infused with molten gold. The coping thickness is $250 \mu \mathrm{m}$ for anterior teeth and $350 \mu \mathrm{m}$ for posterior teeth. The margins can be thinned down to $50 \mu \mathrm{m}$ to give a gold micro-margin or a porcelain butt fit produced. Conventional metal-ceramic porcelains are applied to the gold coloured coping. As with the Golden Gate System and Sunrise Crown there is some reflection from the gold coping, which can enhance aesthetics. Unlike conventional cast metal ceramic restorations, tooth preparation can be reduced significantly, it being possible to make crown margins $0.3 \mathrm{~mm}$ wide. However,

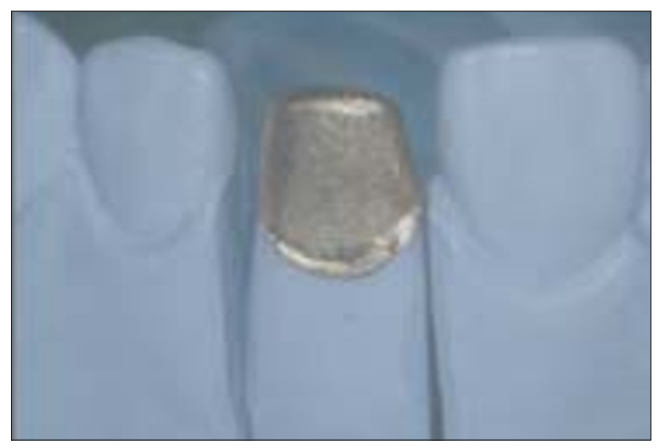

Fig. 5 A Captek coping for a ceramo-metal restoration of a central incisor. The buccal margin will be thinned to a micro-margin prior to porcelain application. Captek is unusual in that it resists firing distortion resulting from differential thermal contraction of metal and porcelain.

our experience with the material shows that it can be difficult to obtain a good crown margin unless an obvious chamfer or shoulder is present.

The manufacturer's literature quotes a study from the University of Boston, which compares restorations, made from Captek with those made from a high quality palladium-containing alloy. The sheer bond strength of porcelain to Captek was almost twice as high whilst crowns of both materials loaded at the incisal edge showed similar load bearing characteristics. Marginal fit was also reported to be excellent and significantly better than conventional
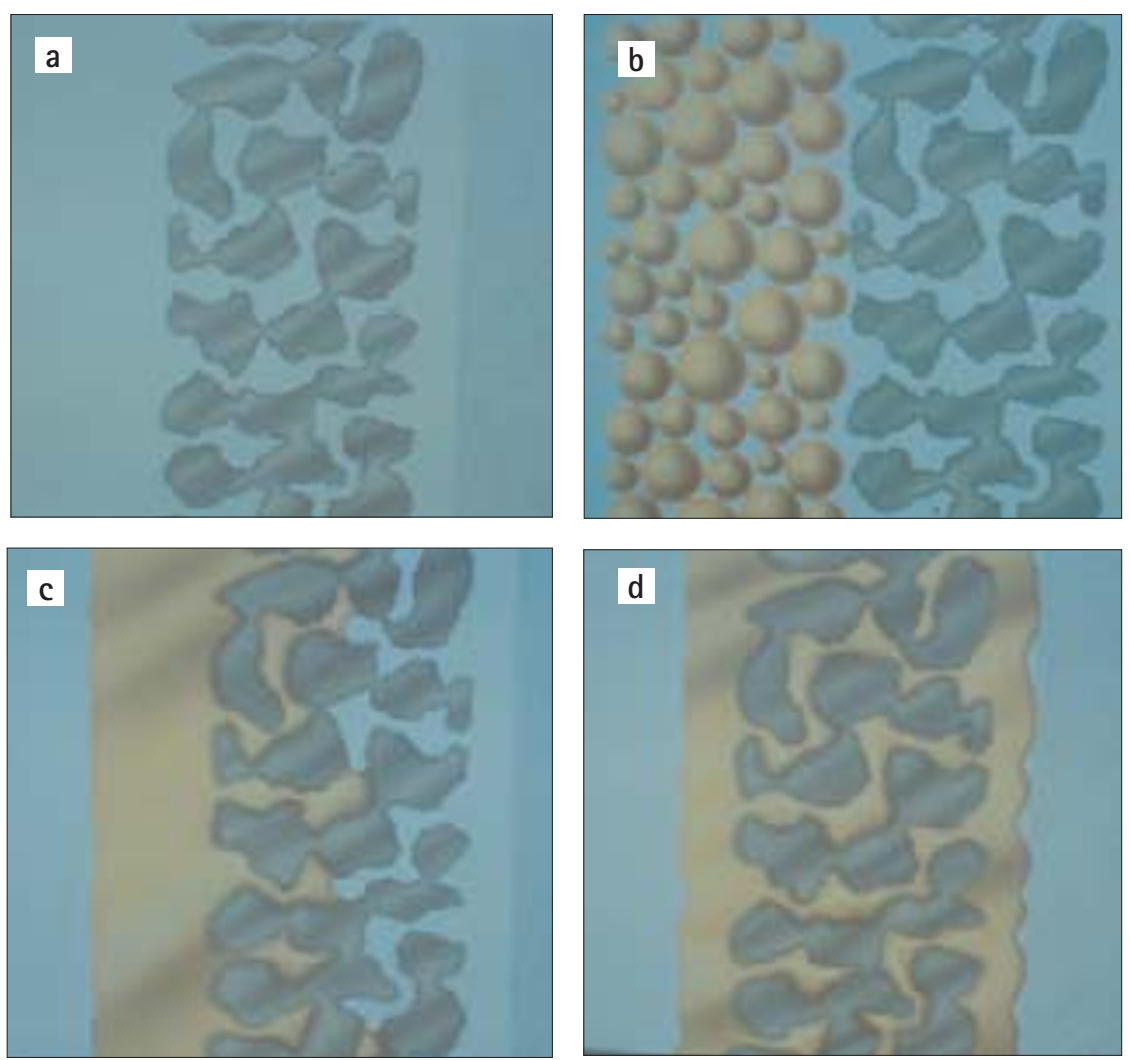

Fig. 6 Schematic diagram showing how a Captek core is laid down as gold alloy impregnated wax sheets: a) the granular appearance of Captek W after the first wax layer has been burnt off; b) application of the second wax layer (Captek G); c) perfusion of the Captek W by the Captek G during the second firing; and d) the resulting composite metal structure after firing (Courtesy of Schottlander). 
metal ceramic crowns. Long-term studies are needed to confirm anecdotal evidence of good clinical performance. Occlusal contacts are usually formed in ceramic, as metal contacts are difficult to build.

\section{Electroformed copings}

The GES Gold Electroforming System uses an ionic solution to electroplate a $0.3 \mathrm{~mm}$ thickness of pure gold directly onto the die. The die is coated with a metallic silver varnish to render it conductive. The manufacturers claim a similar strength characteristic to type III gold but the system is not supported by any clinical studies.

\section{Strengthening of feldspathic metal-ceramic porcelains}

Feldspathic porcelains are inherently weak in tension and strong in compression. Hence they rely on bonding to metal and coping design to dissipate tensile stresses. Another approach is to generate compressive stresses either internally or in the immediate subsurface layer. A recent innovation is the use of ion exchange where smaller diameter sodium ions in the surface of the porcelain are replaced by larger diameter potassium ions. This exchange has the potential to strengthen by subsurface compression, however any strengthening effect is lost if the restoration is subsequently self-glazed or finished. Surprisingly, the ion exchange technique does not give a significantly greater increase in flexural strength than simple overglazing. ${ }^{76}$ Where overglazing is not practical, fine polishing with diamond pastes helps remove surface flaws and gives a modest increase in strength over self-glazing.

\section{RESIN COMPOSITES}

The use of resin composites for indirect inlays and onlays is well known. ${ }^{77}$ Recently, manufacturers have introduced highly filled composite materials for making indirect crowns and bridges. Clearly the major advantage is in reduced laboratory costs, but it should also be born in mind that modern composites induce much less wear against opposing teeth than porcelain. It is too early to say whether these materials will perform well in the long-term, however they at very least offer a good solution where restorations are not expected to last for extended periods eg young patients. Materials falling into this category include Artglass, and Targis and Vectris. The Vectis material is interesting in that it uses a silanated glass fibre mat reinforcement for crowns and glass fibre strands to give strength to bridge spans.

Finally, several systems have been developed for bonding composite to metal substructures. These include the Silicoater and Kevloc techniques which both require specialised laboratory equipment. Restorations of this type are more popular in continental Europe than in the UK where metal-ceramics predominate.

\section{CONCLUSION}

With more and more materials being introduced it is important that dentists understand the variety available and the factors which will contribute to the success or failure of their restorations. In the final analysis established or promising materials should be subjected to randomised clinical trial. Several manufacturers are adopting this approach but more need to do so. While there is considerable clinical research data on intra-coronal restorations much more is needed on those placed extra-coronally.

1. O'Brien W. Evolution of dental casting. In: Valega T, editor. Alternatives to gold alloys in dentistry, Conf. Proc. DHEW Pub. No. [NIH]77-1227. Washington DC: U.S. Government Printing Office, 1977.

2. Craig G, O'Brien W, Powers J. Dental Materials properties and manipulation. pp.236-250. St Louis: Mosby, 1983.

3. Cohen S, Kakar A, Vaidyanathan T, Viswanadhan T. Castability optimization of palladium based alloys. J Prosthet Dent 1996; 76: 125-131.

4. Marzouk M, Saleh L, Emanuel R, Malone W. Clinical behaviour of silver-palladium alloy castings: a five year comparative clinical study. J Prosthet Dent 1991; 65: 19-26.

5. Kansu G, Aydin A. Evaluation of the biocompatibility of various dental alloys: part II - allergenical potentials. Eur J Prosthodont Rest Dent 1996: 4: 155-161.

6. Mulders C, Darwish M, Holze R. Corrosion behaviour of dental alloys - an in-vitro study. J Oral Rehabil 1996; 23: 825-831.

7. Frykholm K, Frithiof L, Fernström A, Moberger G, Blohm S, Björn E. Allergy to copper derived from dental alloys as a possible cause of oral lesions of lichen planus. Acta Dermato-Venereologica 1969; 49: 268-281.

8. Smart E, Macleod R, Lawrence C. Resolution of lichen planus following removal of amalgam restorations in patients with proven allergy to mercury salts: a pilot study. Br Dent J 1995; 178: 108-112.

9. Pierce L, Goodkind R. A status report of the possible risks of base metal alloys and their components. J Prosthet Dent 1989; 62: 234-237.

10. Northeast S E, van Noort R, Johnson A, Winstanley R B, White GE. Metal-ceramic bridges from commercial dental laboratories: alloy composition, cost and quality of fit. $\mathrm{Br}$ Dent J 1992; 172: 198-204.

11. Nery S, McCabe J F, Wassell R W. A comparative study of three dental adhesives. J Dent 1994; 23: 55-61.

12. Weiss $P$. New design parameters: utilising the properties of Ni-Cr super alloys. Dent Clin NAm 1977; 21: 749.

13. Kelly J, Rose T. Nonprecious alloys for use in fixed prosthodontics: a literature review. J Prosthet Dent 1983; 49: 363-370.

14. Equipment. CoDMla. Report on base metal alloys for crown and bridge applications: benefits and risks. J Am Dent Assoc 1985; 111: 479-483

15. Wiltshire W, Ferriera M, Ligthelm A J. Allergies to dental materials. Quintessence Int 1996; 27: 513-520.

16. Ida K, Togaya T, Tsutsumi S, Takeuchi M. Effect of magnesia investments in the dental casting of pure titanium or titanium alloys. Dent Mater J 1982; 1: 8-21.

17. Ida K, Tani Y, Tsutsumi S. Clinical application of pure Ticrowns. Dent Mater J 1985; 4: 191-195.

18. Andersson $M$, Bergman $B$, Bessing $C$, Ericson $G$, Lundquist $P_{\text {, }}$ Nilson $\mathrm{H}$. Clinical results with titanium crowns fabricated with machine duplication and spark erosion. Acta Odontol Scand 1989; 47: 279-286

19. Bergman $B$, Bessing $C$, Ericson $G$, Lundquist $P$, Nilson $H$, Andersson M. A two year follow up study of titanium crowns. Acta Odontol Scand 1990; 48: 113-117.

20. Michalske T, Freiman S. A molecular interpretation of stress corrosion in silica. Nature 1982; 295: 511-512.

21. McClean J, Hughes T. The reinforcement of dental porcelain with ceramic oxides. Br Dent J 1965; 119: 251-267.

22. Denry I. Recent advances in ceramics for dentistry. Crit Rev Oral Biol Med 1996; 7: 134-143.

23. Jones D, Wilson H J. Some properties of dental ceramics. J Oral Rehabil 1975; 2: 379-396.

24. Anusavice K, Zang N, Moorhead J. Influence of colorants on crystallization and mechanical properties of lithia-based glass ceramics. Dent Mater 1994; 10: 141-146.

25. Denry I, Rosensteil S. Flexural strength and fracture
RESIN COMPOSITES KEY POINT:

- Improvements in technology (including fibre filler) look promising but require long-term evaluation 
toughness of Dicor glass-ceramic after embedment modification. J Dent Res 1993; 72: 572-576.

26. Geller W K, Kwiatkowski S J. The Willi's glass crown: a new solution in the dark and shadowed zone of aesthetic porcelain restorations. Quintessence Dent Tech 1987; 11: 233-242.

27. Al-Shehri S, Mohammed $\mathrm{H}$, Wilson $\mathrm{C}$. Influence of lamination on the flexural strength of a dental castable glass-ceramic. J Prosthet Dent 1996; 76: 23-28.

28. Dong J, Luthy H, Wohlwend A, Sharer P. Heat-pressed ceramics: technology and strength. Int J Prosthodont 1992; 5: 9-16.

29. Qualtrough A, Piddock V. Dental CAD/CAM: A millstone or a milestone? Dent Update 1995; 22: 200-204.

30. Mormann W, Krejci K. Computer designed inlays after 5 years in situ: clinical performance and scanning electron microscopic evaluation. Quintessence Int 1992; 23: 109-115.

31. Sjögren S, Bergman M, Molin M, Bessing C A. A clinical examination of ceramic (Cerac) Inlays. Acta Odonto/Scand 1992: 50: 171-178

32. Isenberg B P, Essig M E, Leinfelder K F. Three year clinical evaluation of CAD/CAM restorations. J Aesthet Dent 1992; 4: 173-176.

33. Inokoshi S, B. VM, Willems G, Lambrechts P, Braem M, Vanherles $G$. Marginal accuracy of CAD/CAM inlays made with the original and the updated software. J Dent 1992; 20: 171-177.

34. Thompson J, Bayne S, Heymann H. Mechanical properties of new mica-based machinable glass ceramic of CAD/CAM restorations. J Prosthet Dent 1996; 76: 619-623.

35. Tinschert J, Zwez D, Marx R, Anusavice KJ. Structural reliability of alumina-, feldspar-, leucite-, mica- and zirconia-based ceramics. J Dent 2000; 28: 529-535.

36. Wagner W, Chu T. Biaxial flexural strength and indentation toughness of three new dental core ceramics. J Prosthet Dent 1996; 76: 140-141.

37. Brunton PA, Smith P, McCord J F, Wilson N H F. Procera allceramic crowns: a new approach to an old problem. BrDent 1999; 186: 430-434

38. ISO. International standard 6872-1984. Dental Ceramic. 1st ed.pp.1-14. Geneva, Switzerland: International Organisation for Standardization, 1984.

39. Ban S, Anusavice K J. Influence of test method on failure stress of brittle dental materials. J Dent Res 1990; 69: 1791-1799.

40. McClean J, Jeansonne E, Chiche G, Pinault A. All ceramic crowns and foil crowns. In:Chiche G, Pinault A, editors. Esthetics of anterior fixed prosthodontics. pp.97-113. Chicago: Quintessence Publishing Co., Inc., 1994.

41. Brandson S J, King PA. The impact fracture resistance of restored endodontically treated anterior teeth. J Dent Res 1992; 72: 1141.

42. Madani M, Chu F C, McDonald A V, Smales R J. Effects of surface treatments on shear bond strengths between a resin cement and an alumina core. J Prosthet Dent 2000; 83 644-647.

43. Blixt M, Adamczak E, Linden L A, Oden A, Arvidson K. Bonding to densely sintered alumina surfaces: effect of sandblasting and silica coating on shear bond strength of luting cements. Int J Prosthodont 2000; 13: 221-226.

44. Karlsson S. The fit of Procera titanium crowns. Acta Odontol Scand 1993: 51: 129-134.

45. McClean J W, von Fraunhofer J A. The estimation of cement film thickness by an in vivo technique. Br Dent J 1971; 131: 107-111.

46. Christensen G J. Marginal fit of gold inlay castings. J Prosthet Dent 1966; 16: 297-305.

47. White S N, Kipnis V. Influence of marginal opening on microleakage of cemented artificial crowns. J Prosthet Dent 1994; 71: 257-264

48. Björn AL, Björn H, Grkovik B. Marginal fit of restorations and its relation to periodontal bone level. Odont Rev 1970; 21: 337-346.

49. 147/242. PoCN, Morris H F. Department of Veterans Affairs Cooperative Studies Project No. 242. Quantitative and qualitative evaluation of cast ceramic, porcelain-shoulder, and cast metal full crown margins. J Prosthet Dent 1992; 67: 198-203.

50. Holmes R J, Sulik W D, Holland G A, Bayne S C. Marginal fit of castable ceramic crowns. J Prosthet Dent 1992; 67: 594-599.

51. Castellani D, Baccetti T, Clauser C, Bernadini U D. Thermal distortion of different materials in crown construction. $J$ Prosthet Dent 1994; 72: 360-366.

52. Shearer B, Gough M B, Setchell D J. Influence of marginal configuration and porcelain addition on the fit of In-Ceram crowns. Biomater 1996; 17: 1891-1895.

53. Ratledge $D$, Smith B, Wilson $R$. The effect of restorative materials on the wear of human enamel. J Prosthet Dent 1994; 72: 194-203.

54. Monasky G, Taylor D. Studies on the wear of porcelain, enamel and gold. J Prosthet Dent 1971; 25: 299-306.

55. Seghi R, Rosensteil S, Bauer P. Abrasion of human enamel by different dental ceramics in vitro. J Dent Res 1991; 70: 221-225.

56. Krejci I, Lutz F, Reimer M. Wear of CAD/CAM ceramic inlays: restorations, opposing cusps and luting cements. Quintessence Int 1994; 25: 199-207.

57. Hacker C H, Wagner W C, Razoog M E. An in-vitro investigation of the wear of enamel on porcelain and gold in saliva. J Prosthet Dent 1996; 75: 14-17.

58. Al-Hiyasatt A S. An investigation of the wear of human enamel and dental ceramics. [PhD]. University of Glasgow, 1997.

59. Probster L. Four year clinical study of glass infiltrated, sintered alumina crowns. J Oral Rehabil 1996; 23: 147-151.

60. McLaren E A, White S N. Survival of In-Ceram crowns in a private practice: a prospective clinical trial. J Prosthet Dent 2000; 83: 216-22.

61. Oden A, Andersson M, Krystek-Ondracek I, Magnusson D. Five-year clinical evaluation of Procera AllCeram crowns. J Prosthet Dent 1998; 80: 450-6.

62. Brecker SC. Porcelain baked to gold: a new medium in prosthodontics. J Prosthet Dent 1956; 6: 801-810.

63. Weinstein $M$, Weinstein A. Ney Company, assignee. Fused Porcelain-to-metal teeth. US Patent 3,052,982, September 11. 1962.

64. Pang I, Gilbert J, Chai J, Lautenschlager E. Bonding characteristics of low-fusing porcelain bonded to pure titanium and palladium-copper alloy. J Prosthet Dent 1995; 73: $17-25$

65. Walter M, Reppel P D, Boning K, Freesmeyer W B. Six-year follow-up of titanium and high-gold porcelain-fused-tometal fixed partial dentures. J Oral Rehabil 1999; 26: 91-96.

66. Mattmuller A, Wassmann J, Biffar R. Hydrothermal ceramic for porcelain-fused- to-metal crowns: an initial experience report from clinical practice. Quintessence Int 1996; 27: 521-526.

67. McClean J, Sced I. The bonded alumina crown. 1. The bonding of platinum to aluminous dental porcelain using tin oxide coatings. Aust Dent J 1976; 21: 119-127.

68. McClean J, Kedge M, Hubbard J. The bonded alumina crown. 2. Construction using the twin foil technique. Aust Dent J 1976; 21: 262-263.

69. Philp G, Brukl C. Compressive strengths of conventional, twin foil, and all-ceramic crowns. J Prosthet Dent 1984; 52: 215-220.

70. Piddock V, Marquis P, Wilson H. Comparison of the strengths of aluminous porcelain fired onto platinum and palladium foils. J Oral Rehabil 1991; 13: 31-37.

71. Southan D. Defects in porcelain at the porcelain-to-metal interface. In:Yamada H, Grenoble P, editors. Dental porcelain: the state of the art-1977. pp.48-49. Los Angeles: University of Southern California, 1977.

72. Hopkins K. A method of strengthening aluminous porcelain jacket crowns. Br Dent J 1981; 151: 225-227.

73. Hummert T, Barghi N, Berry T. Effect of fitting adjustments on compressive strength of a new foil crown system. J Prosthet Dent 1991; 66: 177-180.

74. Hummert T, Barghi N, Berry T. Postcementation marginal fit of a new ceramic foil crown system. J Prosthet Dent 1992; 68: 766-770

75. Shoher I, Whiteman A. Captek - A new capillary casting technology for ceramometal restorations. Quintessence Dent Tech 1995: 18: 9-20.

76. Giordano R A, Campbell S, Pober R. Flexural strength of feldspathic porcelain treated with ion exchange, overglaze, and polishing. J Prosthet Dent 1994; 71: 468-472.

77. Burke F, Watts D, Wilson N, Wilson M. Current status and rationale for composite inlays and onlays. Br Dent J 1991; 170: 269-273.

78. EH40/97. Occupational exposure limits 1997 for use with The Control of Substances Hazardous to Health Regulations 1994. pp.14-17. Sudbury: HSE Books, 1997.

79. Seghi R, Daher T, Caputo A. Relative flexural strength of dental restorative ceramics. Dent Mater 1990; 6: 181-184.

80. Seghi R, Sorensen J. Relative flexural strength of six new ceramic materials. Int J Prosthodont 1995; 8: 239-246.

81. Wohlwend A, Strub J Scharer P. Metal ceramic and all porcelain restorations: current considerations. Int J Prosthodont 1989: 2: 13-26. 


\begin{tabular}{ll}
\multicolumn{2}{l}{ List of products mentioned in the text } \\
\hline Alceram & Innotek Dental Corp., Lakewood, USA \\
\hline Artglass & Heraeus Kulzer, Wehrheim, Germany \\
\hline Captek & Schottlander, Letchworth, UK \\
\hline Cerapearl & Kyocera, San Diego, USA \\
\hline Corning MGC-F & Corning Inc., New York, USA \\
\hline Dicor & Corning Inc., New York, USA \\
\hline Dicor MGC & Corning Inc., New York, USA \\
\hline Dicor Plus & Corning Inc., New York, USA \\
\hline Duceratin & Degussa AG, Frankfurt, Germany \\
\hline Duceram-LFC & Degussa AG, Frankfurt, Germany \\
\hline Duceragold & Degussa AG, Frankfurt, Germany \\
\hline GES Gold & Gramm Technology, 75233 Tiefenbronn, Germany \\
\hline Hi-Ceram & Vita Zahnfabrik, D-79704 Bad Säckingen, Germany \\
\hline In-Ceram & Vita Zahnfabrik, D-79704 Bad Säckingen, Germany \\
\hline In-Ceram Spinnel & Vita Zahnfabrik, D-79704 Bad Säckingen, Germany \\
\hline In-Ceram Zirconia & Vita Zahnfabrik, D-79704 Bad Säckingen, Germany \\
\hline IPS Empress & Ivoclar-Vivadent, Schaan, Liechtenstein \\
\hline Kevlock & Heraeus Kulzer GmbH, Wehrheim/Ts, Germany \\
\hline Mirage II & Myron International, Kansas City, USA \\
\hline Optec HSP & Jeneric/Pentron Inc.,Wallingford, USA \\
\hline Procera AllCeram & Nobel Biocare, Göteburg, Sweden \\
\hline Procera Porcelain & Nobel Biocare, Göteburg, Sweden \\
\hline Silicoater & Heraeus Kulzer GmbH, Wehrheim/Ts, Germany \\
\hline Sunrise Foil Crown & Tanaka Dental Products, Skokie, USA \\
\hline Targis/Vectris & Ivoclar-Vivadent, Schaan, Liechtenstein \\
\hline Techceram & Techceram Ltd,, Shipley, UK \\
\hline Vitadur-N & Vita Zahnfabrik, D-79704 Bad Säckingen, Germany \\
\hline & Vita Zahnfabrik, D-79704 Bad Säckingen, Germany \\
\hline
\end{tabular}

